\title{
AIME: Continuing a Legacy of Service to the Science and Engineering Community
}

\author{
Brajendra Mishra
}

The American Institute of Mining, Metallurgical \& Petroleum Engineers (AIME) was founded in 1871 by 22 mining engineers in Wilkes-Barre, Pennsylvania. As one of the first national engineering societies established in the United States, and along with the societies for civil, mechanical, electrical, and chemical engineers, it is known as an Engineering Founder Society. After 85 years, TMS was incorporated as a separate organization in 1957. Thus, AIME is the parent organization of TMS, along with the Society of Petroleum Engineers, the Association for Iron \& Steel Technology and the Society for Mining, Metallurgy \& Exploration.

AIME celebrated its 125 th anniversary at a joint meeting with TMS in Anaheim, California in 1996 and presented a commemorative plaque to the Mayor of Wilkes-Barre, Pennsylvania - its birthplace. TMS, in turn, celebrated its own 50th Anniversary at Walt Disney World in Florida in 2007. At that celebration, AIME leadership participated in the festivities and honored TMS.

Organizationally, AIME is now run by a Board of Trustees comprised of two representatives from each of its member societies. TMS is currently represented by the author, 2011-2012 AIME President Brajendra Mishra (2006 TMS president) and Trustee Ray Peterson (2010 TMS president). In addition, TMS Executive Director Warren Hunt attends the board meetings.

AIME has a very simple mission: to support its four member societies primarily by distributing funds and facilitating interaction with the larger sci- entific and engineering community. It strives to generate funds by responsible fiscal management and provide a forum for communication and interaction by enhancing inter-society collaboration. AIME is also dedicated to honoring the legacy and traditions of AIME.

The values of AIME are succinctly captured in the following six tasks it has undertaken as a result of strategic planning done in 2005: service to customers; productivity; financial responsibility; team relationships; tradition and images; and growth and innovation.

AIME interfaces with the other founder societies of the United Engineering Foundation (UEF)_-IEEE, the American Institute of Chemical Engineers, the American Society of Civil Engineers and the American Society Mechanical Engineers, while representing its member societies. It participates on a collaborative basis to develop projects and programs that benefit the larger engineering community.

AIME's current revenue sources include the investment returns on its approximately $\$ 10$ million endowment, the allocations from the Offshore Technology Conference, and grants received from UEF. AIME has received over $\$ 600,000$ in grants from UEF over the past four years to support technical projects of a multi-disciplinary nature. TMS has led a 3-year project on leadership development (http://emergingleadersalliance.org) and has actively and strongly participated on others that include Carbon Management (http :/fscarbonmanagement.org) and $\mathrm{Ma}$ terials \& Resource Sustainability (http
://www.aimehq.org/news/Welcome.pdf).

A thoughtful management of its finances and prudent streamlining of its activities has allowed AIME to develop a plan to support projects of interest to its member societies with direct dollars (60\% of net revenue-approximately $\$ 420,000$ for 2011). TMS has directed its equal share of the support for 20112012 toward its multi-disciplinary programs emanating from the Materials and Society Committee and has extended opportunities for participation to other members of AIME. To that effect, a multi-society Sustainability Committee has been formed that will chart the course for future team efforts. The projects are expressly focused on materials resource sustainability.

AIME honors its legacy through a significant scholarships and awards program (approximately $\$ 300,000$ annually) which benefits the member societies. TMS regularly honors its members and their service through presentation of awards, such as the Douglas Gold Medal, Champion Mathewson, and Robert Lansing Hardy Awards. TMS recognizes this support annually at its annual meeting awards presentation, which it co-hosts with AIME. TMS and AIME's relationship has always been congenial, strong, and vibrant.

Brajendra Mishra, former TMS president, is Professor and Associate Head of the Metallurgical \& Materials Engineering Department of the Colorado School of Mines. He is associate director of the Kroll Institute for Extractive Metallurgy and the Advanced Coatings and Surface Engineering Laboratory, and Director of the National Science Foundation Industry-University Cooperative Research Center for Resource, Recovery and Recycling.

\section{Brajendra Mishra is a TMS Member!}

To read more about him turn to page 10 To join TMS, visit www.tms.org/Society/Membership.aspx. 